\title{
Peran Readiness for Change Mentality terhadap Kinerja Pegawai Kontrak Industri Alas Kaki
}

\author{
Gazali $^{1}$, Masduki Asbari², Dewiana Novitasari ${ }^{3}$ \\ ${ }^{1,2}$ STMIK Insan Pembangunan, Indonesia \\ e-mail: ${ }^{1}$ rahman.gazali@gmail.com, ${ }^{2}$ kangmasduki.ssi@gmail.com \\ ${ }^{2}$ Universitas Pelita Harapan, Indonesia \\ e-mail: kangmasduki.ssi@gmail.com \\ ${ }^{3}$ Sekolah Tinggi Ilmu Ekonomi Insan Pembangunan, Indonesia \\ e-mail: dhewiediosa@yahoo.co.id
}

\begin{abstract}
Abstrak - Penelitian ini bertujuan untuk mengukur pengaruh kepemimpinan transformasional terhadap kinerja karyawan paruh waktu pada salah satu industri alas kaki di Tangerang, yang dimediasi oleh mentalitas siap berubah. Pengumpulan data dilakukan dengan teknik simple random sampling dan hasil kuesioner yang kembali dan valid adalah 149 sampel. Pemrosesan data menggunakan metode SEM dengan perangkat lunak SmartPLS 3.0. Hasil penelitian ini menyimpulkan bahwa kepemimpinan transformasional tidak berpengaruh signifikan terhadap kinerja karyawan, tetapi kepemimpinan transformasional berpengaruh positif dan signifikan terhadap kesiapan untuk berubah. Penelitian ini menyimpulkan juga bahwa kesiapan untuk perubahan memiliki pengaruh positif dan signifikan terhadap hubungan antara kepemimpinan transformasional dan kinerja karyawan. Mentalitas siap berubah sebagai mediator sepenuhnya. Penelitian baru ini mengusulkan sebuah model untuk membangun kinerja pegawai di antara karyawan paruh waktu dari industri alas kaki di Tangerang melalui peningkatan praktik kepemimpinan transformasional dengan mentalitas siap berubah sebagai mediator. Penelitian ini dapat membuka jalan untuk meningkatkan kesiapan karyawan paruh waktu dalam menghadapi era revolusi industri 4.0.
\end{abstract}

Kata Kunci: Kepemimpinan transformasional; kinerja; readiness for change.

Abstract - This study aims to measure the effect of transformational leadership on part-time employee performance in one of the footwear industries in Tangerang, which is mediated by a ready-to-change mentality. Data collection was carried out using a simple random sampling technique and the questionnaire results were returned and valid were 149 samples. Data processing using the SEM method with SmartPLS 3.0 software. The results of this study concluded that transformational leadership has no significant effect on employee performance, but transformational leadership has a positive and significant effect on readiness to change. This study also concludes that readiness for change has a positive and significant effect on the relationship between transformational leadership and employee performance. The mentality is ready to change as a complete mediator. This new research proposes a model for building employee performance among part-time employees of the footwear industry in Tangerang through enhancing transformational leadership practices with a change-ready mentality as a mediator. This research can pave the way for increasing the readiness of part-time employees in the face of the industrial revolution 4.0 era.

Keywords: Employee performance; readiness for change; transformational leadership.

\section{PENDAHULUAN}

Bagi hampir setiap perusahaan, era revolusi industri 4.0 merupakan fenomena yang mutlak dan tidak bisa dihindari. Perusahaan harus mempunyai strategi yang mampu melakukan transformasi dan inovasi untuk menghadapinya. Ini agar perusahaan dan bisnis yang telah dibangun tidak tergilas oleh zaman dan terhambat perkembangannya (Agistiawati et al., 2020; Nuryanti et al., 2020; Sudiyono et al., 2020; Yuwono et al., 2020). Perusahaan harus sudah memiliki sebuah peta perjalanan yang terintegrasi sehingga arah pengembangan bisnis terlihat dengan jelas. Di antara strategi yang mendesak untuk diperhatikan adalah mentalitas siap berubah (readiness for change) pada diri setiap organisasi, lebih-lebih pada organisasi bisnis global. Kompetisi global era kini meniscayakan mentalitas siap berubah tanpa jeda dari setiap aktor industry. Kondisi pandemi covid-19 yang sedang melanda dunia, tak terkecuali Indonesia, meniscayakan perubahan situasi dan kondisi bisnis mutakhir (Goestjahjanti et al., 2020; Hutagalung, Sopa, et al., 2020; Novitasari, Asbari, Sutardi, et al., 2020; Novitasari, Sasono, \& Asbari, 2020; Novitasari, Sasono, Santoso, et al., 2020). Oleh karena itu, manajemen wajib melakukan langkah- 
langkah praktis dan strategis untuk membawa organisasi keluar dari kubangan krisis yang nyaris menenggelamkan sebagian perusahaan yang tidak menyiapkan diri dengan baik (Asbari, 2015; Asbari, Pramono, et al., 2020; Asbari, Wijayanti, et al., 2019; Bernarto et al., 2020; Novitasari, Asbari, Wijaya, et al., 2020; Purwanto et al., 2020, 2020; Purwanto, Asbari, Prameswari, Ramdan, et al., 2020c).

Tak dapat dipungkiri, bahwa masyarakat Indonesia memiliki semangat patronasi yang kuat. Oleh karena itu, memperhatikan praktik kepemimpinan pada setiap unit sosial masyarakat, apalagi pada organisasi bisnis menjadi penting dan genting (Asbari, 2019; Asbari, Santoso, et al., 2019; Fayzhall, Asbari, Purwanto, Basuki, et al., 2020; Hutagalung, Asbari, et al., 2020; Jumiran et al., 2020; Purwanto, Asbari, Prameswari, Ramdan, et al., 2020c; Yanthy et al., 2020). Walaupun demikian, di lapangan penelitian ditemukan bahwa praktik kepemimpinan transformasional tidak memberikan pengaruh signifikan terhadap kinerja karyawan, sebagaimana beberapa penelitian berikut ini (David et al., 2017; Eliyana et al., 2019; Khalifa Elgelal \& Noermijati, 2014; Makena, 2017; Monoyasa et al., 2017; Putri \& Soedarsono, 2017; Siswatiningsih et al., 2019). Berbeda dengan beberapa penelitian mapan lainnya yang menyebutkan bahwa kepemimpinan transformasional berpengaruh signifikan terhadap Kinerja Pegawai Paruh Waktu (Asbari, 2019; Fayzhall, Asbari, Purwanto, Goestjahjanti, et al., 2020; Jumiran et al., 2020; Maesaroh et al., 2020; Nugroho et al., 2020; Waruwu et al., 2020; Yanthy et al., 2020). Sehubungan masih ada terjadi research gap di dalam hubungan antara kepemimpinan transformasional, Mentalitas Siap Berubahdan kinerja karyawan, maka penelitian ini dipandang perlu untuk dilakukan. Misalnya, penelitian (Mahessa \& NRH, 2016) yang menyebutkan bahwa kepemimpinan berpengarauh positif dan significant terhadap kesiapan untuk berubah, sedangkan penelitian (Susyanto, 2019) secara berbeda menemukan bukti bahwa kepemimpinan transformasional tidak memiliki pengaruh signifikan terhadap Mentalitas Siap Berubahpada karyawan. Oleh karena itu, research gap ini mendorong peneliti untuk mengelaborasi lebih dalam dan meluas tentang hubungan kedua konstruk tersebut.

\section{Kepemimpinan Transformasional}

Kepemimpinan transformasional yang disebutkan oleh (Bass \& Avolio, 2000) sejatinya menyempurnakan teori kepemimpinan transformasional yang sebelumnya disebutkan oleh (Burn, 1978). Para pendukung kepemimpinan transformasional percaya bahwa para pemimpin transformatif menciptakan kepercayaan, kesetiaan, kekaguman, dan rasa hormat di antara para pengikut, dan di antara para pengikut dan para pemimpin, sehingga mereka bersedia secara sukarela untuk mencapai target, tujuan dan visi organisasi. (Robbins, 2001) mengkonfirmasi bahwa pemimpin transformasional adalah mereka yang mampu menginspirasi pengikut mereka untuk mengubah hidup mereka dan bercita-cita untuk tujuan dan visi yang lebih besar. Penjelasan ini telah divalidasi oleh banyak penelitian berikut (Nugroho et al., 2020; Purwanto, Asbari, et al., 2019; Silitonga et al., 2020; Waruwu et al., 2020). Dalam definisi (Luthans, 2005), pemimpin transformatif mampu mengubah kesadaran pengikut mereka, meningkatkan semangat mereka, dan memotivasi mereka untuk melakukan yang terbaik untuk mencapai tujuan organisasi, bukan karena mereka dipaksa untuk, tetapi mereka bersedia. Menurut (Bass \& Avolio, 2000), ada tiga karakteristik pemimpin transformatif, yaitu: pertama, untuk meningkatkan kesadaran pengikut tentang pentingnya proses dan upaya. Kedua, untuk memotivasi pengikut untuk memprioritaskan kepentingan kelompok lebih dari kepentingan individu. Ketiga, untuk mengalihkan kebutuhan pengikut di luar hal-hal materi ke tingkat yang lebih tinggi seperti harga diri dan aktualisasi.

Dengan kata lain, (Burn, 1978) menyatakan bahwa pemimpin transformatif adalah orang-orang yang mendorong pengikut untuk bertindak untuk tujuan tertentu yang mewakili nilai-nilai dan motivasikeinginan dan kebutuhan, aspirasi dan harapan - dari para pemimpin dan pengikut ". Mereka mampu mengubah kesadaran pengikut dan menanamkan nilai-nilai normatif, cita-cita, untuk mencapai moralitas yang lebih tinggi, seperti kesetaraan, kebebasan, keadilan, humanitarianisme, dan kedamaian (Al-Husseini et al., 2019; Choi, 2019; Gashema, 2019; Nguyen et al., 2017; Park \& Pierce, 2020; Yue et al., 2019).

\section{Kesiapan untuk Berubah}

Penelitian yang dilakukan oleh (Holt et al., 2007) menunjukkan bahwa kesiapan untuk perubahan adalah multidimensi yang dipengaruhi oleh keyakinan karyawan bahwa (a) mereka mampu mengimplementasikan perubahan yang diusulkan (yaitu, change efficacy), (b) perubahan yang diusulkan sesuai untuk organisasi (yaitu, appropriateness), (c) para pemimpin berkomitmen untuk perubahan yang diusulkan (yaitu, management support), dan (d) perubahan yang diusulkan bermanfaat bagi organisasi anggota (yaitu, personal benefit). Hasil penelitian ini divalidasi oleh penelitian lain yang menguatkan pendapat (Holt et al., 2007), yakni (Astuti \& Khoirunnisa, 2018; Banjongprasert, 2017; Gelaidan et al., 2016; Katsaros et al., 2020). Masih menurut (Holt et al., 2007), 
indikator yang dapat digunakan untuk mengukur tinggi rendahnya kesiapan untuk berubah karyawan antara lain:

1. Keyakinan karyawan bahwa perubahan yang diusulkan akan tepat bagi organisasi

2. Keyakinan karyawan bahwa organisasi akan mendapatkan keuntungan dari penerapan perubahan

3. Karyawan akan meyakini adanya alasan yang logis untuk berubah dan adanya kebutuhan untuk perubahan yang diusulkan

4. Karyawan berfokus pada manfaat dari perubahan bagi perusahaan

5. Keyakinan karyawan tentang kemampuannya untuk menerapkan perubahan yang diinginkan

6. Karyawan merasa bahwa pemimpin dan manajemen dalam organisasi memiliki komitmen dan mendukung pelaksanaan perubahan yang diusulkan

7. Karyawan merasa bahwa ia akan memperoleh manfaat dari pelaksanaan perubahan yang diusulkan

Untuk mempersiapkan karyawan agar siap berubah pada organisasi maka diperlukan pemahaman mengenai cara-cara yang dapat digunakan dalam menumbuhkan kesiapan untuk berubah. Terdapat dua hal yang dapat dilakukan oleh organisasi yaitu membentuk kesiapan karyawan untuk berubah dan menyelesaikan masalah penolakan untuk berubah (Banjongprasert, 2017). (Hadiyani, 2014; Pramadani, 2012) mengungkapkan bahwa komitmen organisasi dapat mempengaruhi kesiapan untuk berubah. Komitmen organisasi merupakan keinginan untuk tetap menjadi anggota organisasi, kepercayaan dan penerimaan nilai-nilai dan tujuan organisasi serta kesediaan untuk berusaha sebaik mungkin demi kepentingan organisasi. Selain itu employee engagement (keterlibatan kerja) memiliki peranan dalam keberhasilan implementasi perubahan organisasi, terutama yang berskala besar yang melibatkan seluruh elemen dari organisasi. Karyawan yang terlibat dalam kegiatan organisasi akan cenderung mendukung jalannya perubahan organisasi dan siap untuk berubah.

\section{Kinerja Karyawan}

Kinerja adalah perilaku bagaimana target berhasil dicapai (Armstrong \& Taylor, 2014). Kinerja merupakan proses berorientasi tujuan yang diarahkan untuk memastikan bahwa proses-proses keorganisasian ada pada tempatnya untuk memaksimalkan produktivitas para karyawan, tim, dan akhirnya, organisasi (Alrowwad et al., 2017; Do \& Shipton, 2019; Gao et al., 2020; Ng, 2017a, 2017b; Prameswari et al., 2018; Wayan et al., 2018; Zain \& Setiawati, 2019). Pendapat lain, kinerja merupakan apa yang dilakukan atau tidak dilakukan oleh karyawan (Luthans, 2005). Untuk dapat mengetahui kinerja karyawan pada suatu organisasi maka diperlukan beberapa aspek tertentu. Kinerja dipengaruhi oleh variabel yang terkait dengan pekerjaan meliputi role-stress dan konflik kerja/nonkerja (Babin \& Boles, 1998). Terdapat beberapa kriteria dalam mengukur kinerja, yakni: Kualitas, kuantitas, ketepatan waktu, efektivitas biaya dan hubungan antar personal (Bernardin \& Russel, 1993). Sedangkan (Mathis \& Jackson, 2002) menyebutkan bahwa kinerja karyawan memiliki beberapa elemen, yaitu: kuantitas, kualitas, ketepatan, kehadiran, kemampuan kerjasama, dan kesetiaan.

\section{Hubungan antara Kepemimpinan Transformasional dan Kinerja Karyawan}

Studi dari (Asbari, Purwanto, et al., 2019, 2020; Purwanto, Asbari, et al., 2019; Purwanto, Mayesti Wijayanti, et al., 2019) menunjukkan bahwa kepemimpinan transformasional berhubungan positif dengan kinerja organisasi, dengan mediasi atau tanpa variabel mediasi. Penelitian lain juga menemukan temuan serupa, seperti studi dari (Bernarto et al., 2020; Purwanto, Wijayanti, et al., 2019; Purwanto, Asbari, Prameswari, \& Ramdan, 2020b; Purwanto, Asbari, Prameswari, Ramdan, et al., 2020c). Berdasarkan hasil dan kesimpulan penelitian-penelitian sebelummnya, maka peneliti membuat hipotesis sebagai berikut:

$H^{1}$ : Kepemimpinan transformasional memiliki pengaruh terhadap kinerja karyawan.

\section{Hubungan antara Kepemimpinan Transformasional dan Kesiapan Untuk Berubah}

Penelitian terdahulu menyimpulkan bahwa kepemimpinan transformasional tidak berpengaruh signifikan terhadap kesiapan untuk berubah (Susyanto, 2019). Berbeda dengan kesimpulan penelitian (Mahessa \& NRH, 2016) yang menemukan bukti bahwa kepemimpinan memberikan pengaruh positif dan signifikan terhadap kesiapan untuk berubah pada karyawan BPJS Ketenagakerjaan. Demikian juga kesimpulan dari penelitian (Mujiburrahman et al., 2017), (Fitriana \& Sugiyono, 2019), dan (Astuti \& Khoirunnisa, 2018). Berdasarkan hasil kesimpulan penelitian terdahulu, maka penulis menyusun hipotesis kedua sebagai berikut:

$H^{2}$ : Kepemimpinan transformasional memiliki pengaruh terhadap Mentalitas Siap Berubahkaryawan.

\section{Hubungan Mentalitas Siap Berubah dan Kinerja Karyawan}

Kesiapan untuk berubah adalah kepercayaan karyawan bahwa mereka mampu melaksanakan perubahan yang diusulkan (self efficacy (Holt et al., 2007). Dari penjelasan Holt, et al (2007) seorang 
karyawan yang dinyatakan siap untuk berubah akan menunjukkan perilaku menerima, merangkul, dan mengadopsi rencana perubahan yang dilakukan. Sebelum karyawan berada pada posisi siap, karyawan merefleksikan content, context, process, dan atribut individu untuk mempersepsikan dan mempercayai perubahan yang akan dilakukan organisasi. Mentalitas Siap Berubahmenjadi faktor penting dalam menciptakan kesuksesan perubahan (Armenakis et al., 1993). Hal ini dapat ditunjukkan bahwa ketika perubahan dilakukan akan muncul dua sikap yaitu positif dan negatif. Sikap positif ditunjukkan dengan adanya Mentalitas Siap Berubahdan sikap negatif ditunjukkan dengan adanya penolakan terhadap perubahan. Menciptakan sikap positif dalam diri karyawan dapat dilakukan dengan menciptakan Mentalitas Siap Berubahpada diri karyawan sehingga perubahan yang dilakukan dapat mencapai kesuksesan yang diharapkan.

\section{$H^{3}$ : Mentalitas Siap Berubahmemiliki pengaruh terhadap kinerja karyawan.}

\section{Pengaruh Kepemimpinan Transformasional terhadap Kinerja Pegawai Paruh Waktumelalui Mentalitas Siap BerubahSebagai Mediator}

Beberapa penelitian menyimpulkan bahwa variabel kepemimpinan transformasional memiliki hubungan yang signifikan terhadap variabel kinerja karyawan melalui kesiapan untuk berubah (Katsaros et al., 2020). Secara parsial, beberapa penelitian lainnya menyebutkan terhadap pengaruh signifikan kepemimpinan transformasional terhadap kesiapan untuk berubah (Astuti \& Khoirunnisa, 2018; Sari, 2018), dan terdapat pengaruh signifikan kesiapan untuk berubah terhadap kinerja karyawan (Fitriana \& Sugiyono, 2019). Belum banyak penelitian yang memberikan model hubungan mediasi variable kesiapan untuk berubah terhadap hubungan antara variable kepemimpinan transformasional dan variable kinerja karyawan. Oleh karena itu, penulis berupaya untuk menyusun hipotesisi keempat ini sebagai berikut:

$H^{4}$ : Kepemimpinan transformasional memiliki pengaruh terhadap Kinerja Pegawai Paruh Waktumelalui Mentalitas Siap Berubahsebagai mediator.

\section{METODE PENELITIAN}

\section{Definisi Operasional Variabel dan Indikator}

Metode yang digunakan dalam penelitian ini adalah metode kuantitatif. Dilakukan pengumpulan data dengan mengedarkan angket kepada seluruh pegawai paruh waktu pada industry alas kaki di Tangerang. Instrumen yang digunakan untuk mengukur transformational leadership diadaptasi dari (Bogler, 2001) dengan menggunakan 5 items (KT1-KT5). Mentalitas Siap Berubahdiadaptasi dari (Holt et al., 2007) dengan menggunakan 7 items (SB1-SB7). Kinerja Pegawai Paruh Waktudiadaptasi dari (Bernardin \& Russel, 1993) dengan menggunakan 6 items (KP1-KP6). Model penelitian bias dilihat sebagaimana pada Gambar 1. Angket didesain tertutup kecuali untuk pertanyaan/pernyataan mengenai identitas responden yang berupa angket semi terbuka. Tiap item pertanyaan/pernyataan tertutup diberikan lima opsi jawaban, yaitu: sangat setuju (SS) skor 5, setuju (S) skor 4, netral/ ragu-ragu (N) skor 3, tidak setuju (TS) skor 2, dan sangat tidak setuju (STS) skor 1. Metode untuk mengolah data adalah dengan PLS dan menggunakan software SmartPLS versi 3.0 sebagai toolnya.

\section{Populasi dan Sampel}

Populasi dalam penelitian ini adalah pegawai paruh waktu dari salah satu industri alas kaki di Tangerang yang jumlahnya 211 orang. Kuesioner disebarkan dengan teknik simple random sampling. Hasil kuesioner yang kembali sebanyak valid adalah 149 sampel. Jadi jumlah sampel adalah $70.62 \%$ dari jumlah populasi.

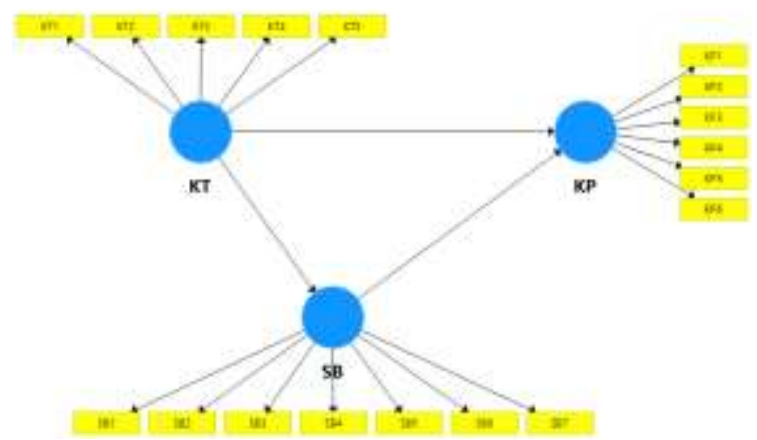

Sumber: Hasil Pengolahan SmartPLS 3.0 (2020)

Gambar 1. Model Penelitian

HASIL DAN PEMBAHASAN

\section{Deskripsi Sampel}

Table 1. Sample Descriptive Information

\begin{tabular}{|l|l|c|c|}
\hline \multicolumn{2}{|c|}{ Kriteria } & Jumlah & $\%$ \\
\hline \multirow{4}{*}{ Usia } & $<30$ thn. & 35 & $23.4 \%$ \\
\cline { 2 - 4 } & $30-40$ thn. & 72 & $48.6 \%$ \\
\cline { 2 - 4 } & $>40$ thn. & 42 & $28.0 \%$ \\
\hline \multirow{2}{*}{$\begin{array}{l}\text { Masa kerja sebagai } \\
\text { karyawan }\end{array}$} & $<5$ thn. & 50 & $33.7 \%$ \\
\cline { 2 - 4 } & $5-10$ thn. & 75 & $50.5 \%$ \\
\cline { 2 - 4 } & $>10$ thn. & 24 & $15.8 \%$ \\
\hline Ijazah tertinggi & SMP & 34 & $22.8 \%$ \\
\hline & SMA & 112 & $75.2 \%$ \\
\hline & $\geq$ S1 & 3 & $2.0 \%$ \\
\hline
\end{tabular}

Sumber: Data Diolah (2020) 


\section{Hasil Uji Validitas dan Reliabilitas Indikator Penelitian}

Tahap pengujian model pengukuran meliputi pengujian validitas konvergen, validitas diskriminan. Sementara untuk menguji reliabilitas konstruk digunakan nilai cronbach's alpha dan composite reliability. Hasil analisis PLS dapat digunakan untuk menguji hipotesis penelitian jika seluruh indikator dalam model PLS telah memenuhi syarat validitas konvergen, validitas deskriminan dan uji reliabilitas.

\section{a. Pengujian Validitas Konvergen}

Uji validitas konvergen dilakukan dengan melihat nilai loading factor masing-masing indikator terhadap konstruknya. Pada sebagian besar referensi, bobot faktor sebesar 0.5 atau lebih dianggap memiliki validasi yang cukup kuat untuk menjelaskan konstruk laten (Chin, 1998; Ghozali, 2014; Hair et al., 2010). Pada penelitian ini batas minimal besarnya loading factor yang diterima adalah 0.5 , dengan syarat nilai AVE setiap konstruk > 0.5 (Ghozali, 2014). Setelah melalui pengolahan SmartPLS 3.0, ada beberapa indikator atau item yang perlu dikeluarkan dari model, yakni: KP1 dan KP3. Selanjutnya, setelah itu, seluruh indikator telah memiliki nilai loading factor di atas 0.5 atau dengan syarat nilai AVE di atas 0.5. Model fit atau valid dari penelitian ini bias dilihat pada Gambar 2. Jadi dengan demikian, validitas konvergen dari model penelitian ini sudah memenuhi syarat. Nilai loadings, cronbach's alpha, composite reliability dan AVE setiap konstruk selengkapnya dapat dilihat Tabel 2 berikut:



Sumber: Hasil Pengolahan SmartPLS 3.0 (2020)

Gambar 2. Model Penelitian Valid

Tabel 2. Items Loadings, Cronbach's Alpha, Composite Reliability, and Average Variance Extracted (AVE)

\begin{tabular}{|c|c|c|c|c|c|}
\hline Varables & Items & Loadings & $\begin{array}{l}\text { Cronbach's } \\
\text { Alpha }\end{array}$ & $\begin{array}{l}\text { Composite } \\
\text { Reliability }\end{array}$ & AVE \\
\hline Kepemimpinan & KT1 & 0.815 & \multirow[t]{5}{*}{0.853} & \multirow[t]{5}{*}{0.895} & \multirow[t]{5}{*}{0.630} \\
\hline \multirow{4}{*}{ Transformasional (KT) } & KT2 & 0.842 & & & \\
\hline & KT3 & 0.809 & & & \\
\hline & KT4 & 0.820 & & & \\
\hline & KT5 & 0.767 & & & \\
\hline \multirow{4}{*}{$\begin{array}{l}\text { Mentalitas Siap Berubah } \\
\text { (SB) }\end{array}$} & SB1 & 0.754 & \multirow[t]{4}{*}{0.917} & \multirow[t]{4}{*}{0.934} & \multirow[t]{4}{*}{0.668} \\
\hline & SB2 & 0.669 & & & \\
\hline & SB3 & 0.854 & & & \\
\hline & SB4 & 0.850 & & & \\
\hline
\end{tabular}




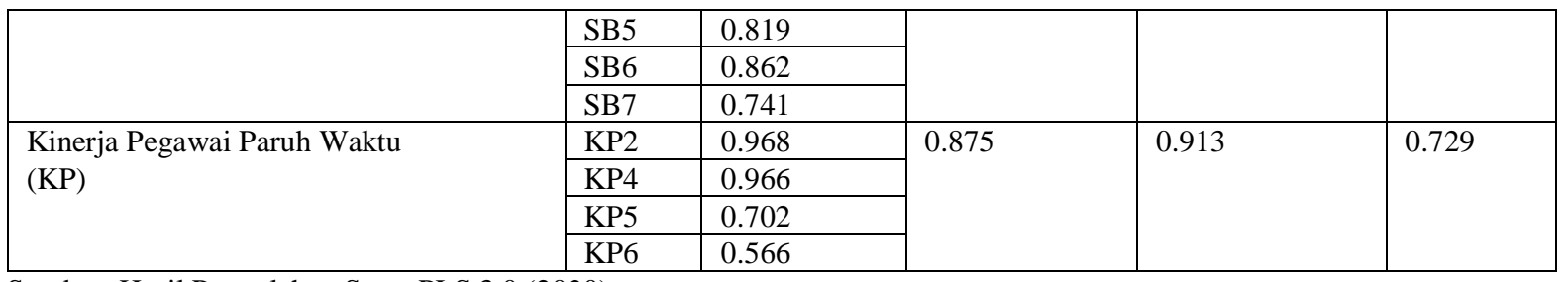

Sumber: Hasil Pengolahan SmartPLS 3.0 (2020)

Tabel 3. Discriminant Validity

\begin{tabular}{|l|l|l|l|}
\hline Variables & KP & KT & SB \\
\hline Kinerja Pegawai Paruh Waktu W (KP) & $\mathbf{0 . 8 5 4}$ & & \\
\hline Kepemimpinan Transformasional (KT) & 0.365 & $\mathbf{0 . 7 9 4}$ & \\
\hline Mentalitas Siap Berubah (SB) & 0.464 & 0.800 & $\mathbf{0 . 8 1 7}$ \\
\hline
\end{tabular}

Sumber: Hasil Pengolahan SmartPLS 3.0 (2020)

Tabel 4. Collinearity Statistics (VIF)

\begin{tabular}{|l|l|l|}
\hline Variables & $\begin{array}{l}\text { Mentalitas Siap Berubah } \\
(\text { SB })\end{array}$ & $\begin{array}{l}\text { Kinerja Pegawai Paruh Waktu } \\
(\text { KP) }\end{array}$ \\
\hline Mentalitas Siap Berubah (SB) & & 2.777 \\
\hline Kepemimpinan Transformasional (KT) & 1.000 & 2.777 \\
\hline
\end{tabular}

Sumber: Hasil Pengolahan SmartPLS 3.0 (2020)

\section{b. Pengujian Validitas Deskriminan}

Discriminant validity dilakukan untuk memastikan bahwa setiap konsep dari masing-masing variabel laten berbeda dengan variabel laten lainnya. Model mempunyai discriminant validity yang baik jika nilai kuadrat AVE masing-masing konstruk eksogen (nilai pada diagonal) melebihi korelasi antara konstruk tersebut dengan konstruk lainnya (nilai di bawah diagonal) (Ghozali, 2014). Hasil pengujian discriminant validity adalah dengan menggunakan nilai kuadrat AVE, yakni dengan melihat FornellLarcker Criterion Value diperoleh sebagaimana ditunjukkan pada Tabel 3.

Hasil uji validitas deskriminan pada tabel 3 di atas menunjukkan bahwa seluruh konstruk telah memiliki nilai akar kuadrat AVE di atas nilai korelasi dengan konstruk laten lainnya (melalui kriteria FornellLarcker). Demikian juga nilai cross-loading seluruh item dari suatu indikator lebih besar dari item indikator lainnya sebagaimana disebut pada Tabel 4, sehingga dapat disimpulkan bahwa model telah memenuhi validitas deskriminan (Fornell \& Larcker, 1981).

Selanjutnya, evaluasi kolinearitas dilakukan untuk mengetahui apakah ada kolinearitas dalam model. Untuk menemukan collinearity, diperlukan penghitungan VIF dari setiap konstruk. Jika skor VIF lebih tinggi dari 5, maka model tersebut memiliki collinearity (Hair et al., 2014). Sebagaimana ditunjukkan pada Tabel 4, semua skor VIF lebih kecil dari 5, artinya bahwa model ini tidak memiliki masalah collinearity.

\section{c. Pengujian Reliabilitas Konstruk}

Reliabilitas konstruk dapat dinilai dari nilai cronbach's alpha dan composite reliability dari masing-masing konstruk. Nilai composite reliability dan cronbach's alpha yang disarankan adalah lebih dari 0.7 (Ghozali, 2014). Hasil uji reliabilitas pada tabel 2 di atas menunjukkan bahwa seluruh konstruk telah memiliki nilai composite reliability dan cronbach's alpha lebih besar dari 0.7 (> 0.7 ). Kesimpulannya, seluruh konstruk telah memenuhi reliabilitas yang dipersyaratkan.

\section{Pengujian Hipotesis}

Pengujian hipotesis dalam PLS disebut juga sebagai uji inner model. Uji ini meliputi uji signifikansi pengaruh langsung dan tidak langsung serta pengukuran besarnya pengaruh variabel eksogen terhadap variabel endogen. Untuk mengetahui pengaruh kepemimpinan transformasional terhadap Kinerja Pegawai Paruh Waktudengan melalui Mentalitas Siap Berubahsebagai variable mediasi dibutuhkan uji pengaruh langsung dan tidak langsung. Uji pengaruh dilakukan dengan menggunakan uji t-statistik dalam model analisis partial least squared (PLS) dengan menggunakan bantuan software SmartPLS 3.0. Dengan teknik boothstrapping, diperoleh nilai $R$ Square dan nilai uji signifikansi sebagaimana Tabel 5 dan Tabel 6. 
Tabel 5. Nilai $R$ Square

\begin{tabular}{|c|c|c|}
\hline & Square & R Square Adjusted \\
\hline Mentalitas Siap Berubah (SB) & 0.640 & 0.637 \\
\hline Kinerja Pegawai Paruh Waktu (KP) & 0.215 & 0.204 \\
\hline
\end{tabular}

Sumber: Hasil Pengolahan SmartPLS 3.0 (2020)

Tabel 6. Hypotheses Testing

\begin{tabular}{|l|l|l|l|l|l|l|}
\hline Hypotheses & Relationship & Beta & SE & T Statistics & P-Values & Decision \\
\hline H1 & KT -> KP & -0.017 & 0.118 & 0.144 & 0.886 & $\begin{array}{l}\text { Not } \\
\text { Supported }\end{array}$ \\
\hline H2 & KT -> SB & 0.800 & 0.039 & 20.459 & 0.000 & Supported \\
\hline H3 & SB -> KP & 0.477 & 0.097 & 4.928 & 0.000 & Supported \\
\hline H4 & KT -> SB -> KP & 0.382 & 0.086 & 4.444 & 0.000 & Supported \\
\hline
\end{tabular}

Sumber: Hasil Pengolahan SmartPLS 3.0 (2020)

Berdasarkan Tabel 5, nilai $R$ Square Mentalitas Siap Berubah (SB) sebesar 0.640 yang berarti bahwa variable Mentalitas Siap Berubah (SB) mampu dijelaskan oleh variabel kepemimpinan transformasional (KT) sebesar 64.0\%, sedangkan sisanya sebesar $36.0 \%$ dijelaskan oleh variabel lain yang tidak dibahas dalam penelitian ini. Nilai $R$ Square Kinerja Pegawai Paruh Waktu (KP) sebesar 0.215 yang berarti bahwa variabel Kinerja Pegawai Paruh Waktu (KP) mampu dijelaskan oleh variabel kepemimpinan transformasional (KT) dan Mentalitas Siap Berubah (SB) sebesar 21.5\%, sedangkan sisanya sebesar $78.5 \%$ dijelaskan oleh variabel lain yang tidak dibahas dalam penelitian ini. Sedangkan Tabel 6 menampilkan $t$-statistics dan $p$ values yang menunjukkan pengaruh antar variable penelitian yang telah disebutkan.

\section{Pengaruh Kepemimpinan Transformasional terhadap Kinerja Pegawai Paruh Waktu}

Berdasarkan penghitungan statistic yang diringkas pada Tabel 6 di atas, disimpulkan bahwa kepemimpinan transformasional tidak secara signifikan mempengaruhi kinerja pegawai paruh waktu di industry alas kaki. Terbukti dengan nilai tstatistics 0.144 lebih kecil dari 1.96 dan nilai $p$-values sebesar 0.086 lebih besar dari 0.05. Artinya, hipotesis pertama (H1) ditolak atau tidak diterima. Temuan ini bertentangan dengan hasil penelitian sebelumnya dari (Asbari, 2019; Asbari, Purwanto, et al., 2019; Asbari, Santoso, et al., 2019; Asbari, Purwanto, et al., 2020; Asbari, Fayzhall, et al., 2020; Fayzhall, Asbari, Purwanto, Basuki, et al., 2020; Fayzhall, Asbari, Purwanto, Goestjahjanti, et al., 2020; Purwanto, Asbari, et al., 2019; Purwanto, Mayesti Wijayanti, et al., 2019; Purwanto, Wijayanti, et al., 2019; Purwanto, Bernarto, Asbari, Mayesti Wijayanti, et al., 2020d; Purwanto, Asbari, Budi Santoso, Mayesti Wijayanti, et al., 2020a;
Purwanto, Pramono, Asbari, Senjaya, et al., 2020e; Purwanto, Asbari, Prameswari, Ramdan, et al., 2020c; Purwanto, Asbari, \& Hadi, 2020b, 2020a; Purwanto, Asbari, Prameswari, \& Ramdan, 2020b). Seperti disebutkan sebelumnya, proses transformasi di industri sebagai indikator utama untuk variabel kepemimpinan transformasional hanya berlangsung untuk waktu yang cukup singkat. Transformasi dimulai dengan perubahan struktur organisasi, pengangkatan pemimpin baru, dan kemudian perubahan sistem kerja dan budaya. Responden penelitian ini merasa bahwa Kinerja Pegawai Paruh Waktudi industri tidak dipengaruhi oleh perubahan di atas, karena prosesnya berlangsung untuk waktu yang cukup singkat. Walaupun demikian, penelitian ini sejalan dengan kesimpulan dari penelitian (Fayzhall, Asbari, Purwanto, Basuki, et al., 2020; Fayzhall, Asbari, Purwanto, Goestjahjanti, et al., 2020; Hutagalung, Asbari, et al., 2020; Purwanto, Mayesti Wijayanti, et al., 2019; Purwanto, Wijayanti, et al., 2019; Purwanto, Asbari, \& Hadi, 2020a, 2020b; Purwanto, Asbari, Prameswari, \& Ramdan, 2020b) yang menemukan bukti bahwa kepemimpinan tidak berpengaruh signifikan terhadap kinerja. Temuan ini telah memberikan umpan balik yang bermanfaat bagi manajemen industri yang mencoba untuk memulai perubahan, di mana proses tersebut membutuhkan upaya sosialisasi dan diseminasi yang konstan, sehingga setiap anggota organisasi memahami sepenuhnya kebutuhan akan perubahan tersebut, dan pada gilirannya akan mendukung proses. Temuan yang berbeda juga disebabkan oleh konteks yang berbeda antara organisasi publik dan swasta, juga berbeda antara organisasi jasa dan industri.

\section{Pengaruh Kepemimpinan Transformasional terhadap Kesiapan untuk Berubah}

Berdasarkan penghitungan statistic yang diringkas pada Tabel 6 di atas, disimpulkan bahwa kepemimpinan transformasional secara positif dan 
signifikan mempengaruhi mentalitas siap berubah pada karyawan di industry alas kaki. Terbukti dengan nilai $t$-statistics 20.459 lebih besar dari 1.96 dan nilai $p$-values sebesar 0.000 lebih kecil dari 0.05 . Artinya, hipotesis kedua (H2) diterima. Temuan ini sesuai dengan kesimpulan temuan empiris dan teoritis dari penelitian sebelumnya yang mengonfirmasi bahwa kepemimpinan transformasional secara signifikan mempengaruhi mentalitas siap berubah pada karyawan (Astuti \& Khoirunnisa, 2018; Fitriana \& Sugiyono, 2019; Mahessa \& NRH, 2016).

\section{Pengaruh Mentalitas Siap Berubah terhadap Kinerja Pegawai Paruh Waktu}

Berdasarkan penghitungan statistic yang diringkas pada Tabel 6 di atas, disimpulkan bahwa Mentalitas Siap Berubahsecara positif dan signifikan mempengaruhi Kinerja pegawai paruh waktu di industri. Terbukti dengan nilai $t$-statistics 4.928 lebih besar dari 1.96 dan nilai $p$-values sebesar 0.000 lebih kecil dari 0.05. Artinya, hipotesis ketiga (H3) diterima. Kesimpulan penelitian ini mendukung apa yang telah ditemukan pada penelitian sebelumnya, bahwa Mentalitas Siap Berubahberpengaruh positif dan signifikan terhadap kinerja (Banjongprasert, 2017; Katsaros et al., 2020).

\section{Pengaruh Kepemimpinan Transformasional terhadap Kinerja Pegawai Paruh Waktu melalui Mentalitas Siap Berubah sebagai Mediator}

Berdasarkan penghitungan statistic yang diringkas pada Tabel 6 di atas, disimpulkan bahwa Mentalitas Siap Berubahsecara positif dan signifikan mempengaruhi Kinerja Pegawai Paruh Waktumelalui Mentalitas Siap Berubahpada karyawan di industri. Terbukti dengan nilai $t$-statistics 4.444 lebih besar dari 1.96 dan nilai $p$-values sebesar 0.000 lebih kecil dari 0.05. Artinya, hipotesis ketiga (H4) diterima. Kesimpulan penelitian ini mendukung apa yang telah ditemukan pada penelitian sebelumnya yang menyimpulkan bahwa Mentalitas Siap Berubahmampu memediasi hubungan pengaruh kepemimpinan terhadap kinerja karyawan (Katsaros et al., 2020)

\section{KESIMPULAN}

Berdasarkan hasil penelitian ini, disimpulkan bahwa kepemimpinan transformasional tidak memberikan pengaruh yang signifikan terhadap tinggi-rendahnya tingkat Kinerja Pegawai Paruh Waktudi industry alas kaki. Tetapi, ternyata keyakinan dan semangat mentalitas siap berubah pada diri karyawan mampu mempertahankan tetap baiknya kinerja. Ada hal menarik yang bias diperhatikan dari hasil penelitian ini, bahwa di era pandemic Covid-19 ini, praktik kepemimpinan transformasional tidak berpengaruh signifikan terhadap kinerja karyawan, tetapi berpengaruh positif dan signifikan terhadap kesiapan untuk berubah. Mengapa demikian? Jawabannya bisa jadi karena masa pandemic covid-19 ini telah menumbuhkan sadarkan kemandirian para pegawai untuk berupaya maksimal bertahan dalam melakukan pekerjaannya. Oleh karena itu, keberadaan praktik kepemimpinan transformasional sudah tidak banyak memberikan pengaruh terhadap kinerja karyawan, karena mereka sudah relative lebih mandiri. Di sisi lain, kepemimpinan transformasional mampu memberikan pengaruh yang positif dan signifikan terhadap Mentalitas Siap Berubahpada diri karyawan di masa pandemic covid-19 ini, mengapa demikian? Jawabannya, di dalam praktik kepemimpinan, terdapat dimensi keteladan dan mempengaruhi yang sangat dominan. Briefing dan sesi rapat yang kerap diadakan oleh pemimpin mampu memunculkan kesadaran dan keyakinan kuat kepada karyawan bahwa pandemic covid-19 ini akan bisa berakhir dan normal kembali. Di samping itu, motivasi yang diberikan oleh pemimpin transformasional memberikan keyakinan bahwa pasca pandemic, perusahaan akan memiliki kinerja lebih lagi karena mampu melihat peluang-peluang baru di masa depan. Di samping itu, penelitian ini menemukan bukti bahwa Mentalitas Siap Berubahmampu menjadi mediasi penuh terhadap hubungan antara kepemimpinan transformasional dan kinerja karyawan.

Berdasarkan hasil temuan penelitian ini, disarankan kepada manajemen industry alas kaki untuk memperhatikan praktik kepemimpinan transformasional yang lebih baik sehingga tetap mampu memberikan dampak positif terhadap kinerja pegawai paruh waktu, atau jika tidak mungkin mempertahankan praktik kepemimpinan transformasional lagi, manajemen perlu mempertimbangkan praktik gaya kepemimpinan baru yang lebih sesuai dengan kondisi karyawan paruh waktu di industry alas kaki saat ini yang mayoritas sudah dewasa $(76.59 \%)$ dan masa kerja sudah cukup lama, yang sudah di atas 5 tahun sebanyak $66.34 \%$. Berikutnya, manajemen perlu mempertahankan kebiasaan memberikan briefing dan motivasi para pemimpin di perusahaan untuk terus menjaga Mentalitas Siap Berubahpada diri karyawan, lebihlebih di masa pandemic Covid-19 ini. Karena Mentalitas Siap Berubahadalah modal dasar dari kesiapan karyawan untuk menghadapi kompetisi di era revolusi industry 4.0.

Penelitian ini memiliki beberapa keterbatasan. Pertama, penelitian ini menganalisis pengaruh kepemimpinan transformasional terhadap kinerja pegawai paruh waktu baik secara langsung maupun tidak langsung melalui variabel kesiapan untuk berubah. Karena mungkin ada beberapa 
variabel lain (seperti motivasi, kompetensi, manajemen pengetahuan, budaya organisasi, dll) yang mempengaruhi kinerja karyawan. Penulis sangat merekomendasikan untuk menemukan, mengeksplorasi, dan menganalisisnya pada penelitian-penelitian berikutnya. Kedua, penelitian ini dilakukan di industri pabrikan alas kaki dan mungkin tidak bisa digeneralisasi ke industri lain. Oleh karena itu, sangat disarankan untuk melakukan penelitian lebih lanjut tentang topik ini di industri lain. Mungkin dapat ditambahkan ke seluruh wilayah, atau di negara lain, atau diperbandingan antara UKM dan organisasi besar.

\section{REFERENSI}

Agistiawati, E., Asbari, M., Basuki, S., Yuwono, T., \& Chidir, G. (2020). Exploring the Impact of Knowledge Sharing and Organizational Culture on Teacher Innovation Capability. International Journal of Science and Management Studies (IJSMS), 3(3), 62-77. http://www.ijsmsjournal.org/current-issue.html

Al-Husseini, S., El Beltagi, I., \& Moizer, J. (2019). Transformational leadership and innovation: the mediating role of knowledge sharing amongst higher education faculty. International Journal of Leadership in Education, $\quad 00(00), \quad 1-24$. https://doi.org/10.1080/13603124.2019.15883 81

Alrowwad, A., Obeidat, B. Y., Tarhini, A., \& Aqqad, N. (2017). The Impact of Transformational Leadership on Organizational Performance via the Mediating Role of Corporate Social Responsibility: A Structural Equation Modeling Approach. International Business Research, 10(1), 199-221. https://doi.org/10.5539/ibr.v10n1p199

Armenakis, A. A., Harris, S. G., \& Mossholder, K. W. (1993). Creating Readiness for Organizational Change. Human Relations, 46(6), 681-703. https://doi.org/https://doi.org/10.1177/001872 679304600601

Armstrong, M., \& Taylor, S. (2014). Human Resource Management Practice. Ashford Colour Press Ltd.

Asbari, M. (2015). Fokus Satu Hebat. Penerbit Dapur Buku.

Asbari, M. (2019). Pengaruh kepemimpinan transformasional dan iklim organisasi terhadap kinerja dosen. JOCE IP, 13(2), 172-186. http://jurnal.ipem.ac.id/index.php/joceip/article/view/187

Asbari, M., Fayzhall, M., Goestjahjanti, F. S., Winanti, Yuwono, T., Hutagalung, D., Basuki, S., Maesaroh, S., Mustofa, Chidir, G., Yani, A., \& Purwanto, A. (2020). Peran Kepemimpinan Transformasional Dan Organisasi
Pembelajaran Terhadap Kapasitas Inovasi Sekolah. EduPsyCouns: Journal of Education, Psychology and Counseling, 2(1), 6724-6748. https://ummaspul.ejournal.id/Edupsycouns/article/view/421

Asbari, M., Pramono, R., Kotamena, F., Juliana, Sihite, O. B., Alamsyah, V. U., Imelda, D., Setiawan, S. T., \& Purwanto, A. (2020). Bekerja Sambil Kuliah dalam Perspektif SelfManagement (Studi Etnografi pada Karyawan Etnis Jawa di Kota Seribu Industri Tangerang). Edumaspul - Jurnal Pendidikan, 4(1), 1-10. https://doi.org/https://doi.org/10.33487/eduma spul.v4i1.363

Asbari, M., Purwanto, A., \& Budi, P. (2020). Pengaruh Iklim Organisasi dan Kepemimpinan Transformasional Terhadap Produktivitas Kerja Inovatif Pada Industri Manufaktur di Pati Jawa Tengah . Jurnal Produktivitas, 7(1), 6269.

https://doi.org/http://dx.doi.org/10.29406/jpr.v $7 \mathrm{i} 1.1797$

Asbari, M., Purwanto, A., \& Santoso, P. B. (2019). Influence of Leadership, Motivation, Competence, Commitment and Culture on ISO 9001:2015 Performance in Packaging Industry. Scholars Journal of Economics, Business and Management, 6(12), 577-582. https://doi.org/10.36347/sjebm.2019.v06i12.0 05

Asbari, M., Santoso, P. B., \& Purwanto, A. (2019). Pengaruh Kepemimpinan dan Budaya Organisasi Terhadap Perilaku Kerja Inovatif pada Industri 4.0. Jim UPB, 8(1), 7-15. https://doi.org/ttps://doi.org/10.33884/jimupb. v8i1.1562

Asbari, M., Wijayanti, L. M., Hyun, C. C., Purwanto, A., Santoso, B., \& Article, H. (2019). Effect of Tacit and Explicit Knowledge Sharing on Teacher Innovation Capability. Dinamika Pendidikan, 14(2), 227-243. https://doi.org/10.15294/dp.v14i2.22732

Astuti, E., \& Khoirunnisa, R. M. (2018). Pengaruh Employee Engagement, Komitmen Organisasi, Dan Kepemimpinan Transformasional Terhadap Kesiapan Untuk Berubah (Readiness For Change) Pada Karyawan Universitas Ahmad Dahlan. JURNAL FOKUS, 8(1), 47-66.

Babin, B. J., \& Boles, J. S. (1998). Employee behavior in a service environment: A model and test of potential differences between men and women. Journal of Marketing, 62(2), 7791. https://doi.org/10.2307/1252162

Banjongprasert, J. (2017). An Assessment of ChangeReadiness Capabilities and Service Innovation Readiness and Innovation Performance : Empirical Evidence from MICE Venues. IJEM International Journal of Economics and Management, 11, 1-17.

Bass, B., \& Avolio, B. (2000). Technical 
Report, Leader form, rater form, and Scoring Key of MLQ From 5x-Short. Mind Garden, Inc. Bernardin, H., \& Russel, J. (1993). Human Resource Management: An Experimental Approach. Mc Graw Hill Companies.

Bernarto, I., Bachtiar, D., Sudibjo, N., Suryawan, I. N., Purwanto, A., \& Asbari, M. (2020). Effect of transformational leadership, perceived organizational support, job satisfaction toward life satisfaction: Evidences from indonesian teachers. International Journal of Advanced Science and Technology, 29(3), 5495-5503. http://sersc.org/journals/index.php/IJAST/artic le/view/6057

Bogler, R. (2001). The influence of leadership style on teacher job satisfaction. Educational Administration Quarterly, 37(5), 662-683. https://doi.org/10.1177/00131610121969460

Burn, J. (1978). Leadership. Harper.

Chin, W. (1998). The Partial Least Squares Approach to Structural Equation Modeling (E. Modern Methods for Business Research, In: G. A. Marcoulides (ed.)). Lawrence Erlbaum Associates Publisher.

Choi, Y. (2019). The mediating role of the aesthetic experience between transformational leadership and innovation. Cogent Business and Management, 6(1). https://doi.org/10.1080/23311975.2019.16626 30

David, S., Armanu, \& Afnan, T. E. (2017). The Effects of Transformational Leadership and Personality on Employee Performance in Nissan Malang Mediated by Organizational Commitment. RJOAS, 3(19), 197-210. https://doi.org/https://doi.org/10.18551/rjoas.2 017-01.21

Do, H., \& Shipton, H. (2019). High-performance work systems and innovation in Vietnamese small firms. International Small Business Journal: Researching Entrepreneurship, 37(7), 732-753. https://doi.org/10.1177/0266242619863572

Eliyana, A., Ma'arif, S., \& Muzakki. (2019). Job satisfaction and organizational commitment effect in the transformational leadership towards employee performance. European Research on Management and Business Economics, 25(3), 144-150. https://doi.org/10.1016/j.iedeen.2019.05.001

Fayzhall, M., Asbari, M., Purwanto, A., Basuki, S., Hutagalung, D., Maesaroh, S., Chidir, G., Goestjahjanti, F. S., \& Andriyani, Y. (2020). Pengaruh Gaya Kepemimpinan Terhadap Kapabilitas Inovasi Guru Dalam Perspektif Organizational Learning. EduPsyCouns: Journal of Education, Psychology and Counseling, 2(1), 64-91. https://ummaspul.ejournal.id/Edupsycouns/article/view/413
Fayzhall, M., Asbari, M., Purwanto, A., Goestjahjanti, F. S., Yuwono, T., Radita, F. R., Yulia, Y., Cahyono, Y., \& Suryani, P. (2020). Transformational versus Transactional Leadership: Manakah yang Mempengaruhi Kepuasan Kerja Guru? EduPsyCouns: Journal of Education, Psychology and Counseling, 2(1), 256-275. https://ummaspul.ejournal.id/Edupsycouns/article/view/463

Fitriana, R., \& Sugiyono. (2019). Kesiapan berubah pada sekretariat jenderal kementerian kelautan dan perikanan republik indonesia. IKRAITH EKONOMIKA VOL, 2(2), 42-51.

Fornell, C., \& Larcker, D. F. (1981). Evaluating Structural Equation Models with Unobservable Variables and Measurement Error. Journal of Marketing Research, 18(1), 39. https://doi.org/10.2307/3151312

Gao, R. (Chuang R., Murphy, W. H., \& Anderson, R. E. (2020). Transformational leadership effects on salespeople's attitudes, striving, and performance. Journal of Business Research, 110(January), 237-245. https://doi.org/10.1016/j.jbusres.2020.01.023

Gashema, B. (2019). How Transformational Leadership Fuels Employee's Creative Performance Behaviors in the Workplace? International Journal of Research in Business and Social Science (2147-4478), 8(4), 144162. https://doi.org/10.20525/ijrbs.v8i4.271

Gelaidan, H. M., Al-swidi, A., \& Mabkhot, H. A. (2016). Employee Readiness for Change in Public Higher Education Institutions : Examining the Joint Effect of Leadership Behavior and Emotional Intelligence Employee Readiness for Change in Public Higher Education Institutions: Examining the Joint Effect of Lead. International Journal of Public Administration, $\quad 00(00), \quad 1-9$. https://doi.org/10.1080/01900692.2016.12559 62

Ghozali, I. (2014). Structural Equation Modeling, Metode Alternatif dengan Partial Least Square (PLS) (4th ed.). Badan Penerbit Universitas Diponegoro.

Goestjahjanti, S. F., Novitasari, D., Hutagalung, D., Asbari, M., \& Supono, J. (2020). Impact of Talent Management, Authentic Leadership and Employee Engagement on Job Satisfaction: Evidence From South East Asian Industries. Journal of Critical Reviews, 7(19), 67-88. http://www.jcreview.com/?mno=101983

Hadiyani, S. (2014). Peranan Komitmen Organisasi dan Employee Engagement terhadap Kesiapan Karyawan untuk Berubah. JURNAL PSIKOLOGI, 4I(1), 17-33.

Hair, J. F., Black, W. C., Babin, B. J., \& Anderson, R. E. (2010). Multivariate Data Analysis (7th ed.). Pearson Prentice Hall.

Hair, J. F., Hult, G. T., Ringle, C. M., \& Sarstedt, M. 
(2014). A primer partial least squaresstructural equation modeling (PLS-SEM). SAGE Publications.

Holt, D. T., Armenakis, A. A., Feild, H. S., \& Harris, S. G. (2007). Readiness for Organizational Change: The Systematic Development of a Scale. The Journal of Applied Behavioral Science, 43(2), 232-255. https://doi.org/10.1177/0021886306295295

Hutagalung, D., Asbari, M., Fayzhall, M., Ariyanto, E., Agistiawati, E., Sudiyono, R. N., Waruwu, H., Goestjahjanti, F. S., Winanti, \& Yuwono, T. (2020). Peran Religiusitas, Kepemimpinan Transformasional, Kepuasan Kerja dan Mediasi Organizational Citizenship Behavior terhadap Kinerja Guru. EduPsyCouns: Journal of Education, Psychology and Counseling, 2(1), 311-326. https://ummaspul.ejournal.id/Edupsycouns/article/view/483

Hutagalung, D., Sopa, A., Asbari, M., Cahyono, Y., Maesaroh, S., \& Chidir, G. (2020). Influence of Soft Skills, Hard Skills and Organization Learning on Teachers' Performance through Innovation Capability as Mediator. Journal of Critical Reviews, 7(19), 54-66. http://www.jcreview.com/?mno=101978

Jumiran, Novitasari, D., Nugroho, Y. A., Sutardi, D., Sasono, I., \& Asbari, M. (2020). Pengaruh Dimensi Kepemimpinan Transformasional terhadap Kepuasan Kerja dan Komitmen Organisasional: Studi Kasus pada Dosen Perguruan Tinggi Swasta. EduPsyCouns: Journal of Education, Psychology and Counseling, 2(1), 600-621. https://ummaspul.ejournal.id/Edupsycouns/article/view/555

Katsaros, K. K., Tsirikas, A. N., \& Kosta, G. C. (2020). The impact of leadership on firm financial performance: the mediating role of employees' readiness to change. Leadership \& Organization Development Journal, 41(3), 333-347.

https://doi.org/https://doi.org/10.1108/LODJ02-2019-0088

Khalifa Elgelal, K. S., \& Noermijati, N. (2014). The Influences of Transformational Leaderships on Employees Performance (A Study of the Economics and Business Faculty Employee at University of Muhammadiyah Malang). Asia Pacific Management and Business Application, 3(1), $48-66$. https://doi.org/10.21776/ub.apmba.2014.003.0 1.4

Luthans, F. (2005). Perilaku Organisasi (11th ed.). Penerbit ANDI.

Maesaroh, S., Asbari, M., Hutagalung, D., Agistiawati, E., Basuki, S., Radita, F. R., Nurasiah, Yulia, Y., Singgih, E., \& Chidir, G. (2020). Pengaruh Religiusitas dan Kepemimpinan Transformasional terhadap
Kinerja Guru melalui Mediasi Organizational Citizenship Behavior. EduPsyCouns: Journal of Education, Psychology and Counseling, 2(1), 276-290. https://ummaspul.ejournal.id/Edupsycouns/article/view/473

Mahessa, N. F., \& NRH, F. (2016). Gaya Kepemimpinan Melayani dan Kesiapan untuk Berubah pada Karyawan BPJS Ketenagakerjaan. Jurnal Empati, 5(1), 113116.

Makena, J. E. (2017). Pengaruh Kepemimpinan Transformasional Terhadap Kinerja Organisasi Melalui Pembelajaran Organisasi dan Inovasi Pada Hotel Prama Sanur Beach Bali. JAGADHITA:Jurnal Ekonomi \& Bisnis, 4(2), 76-88. https://doi.org/10.22225/jj.4.2.135.7688

Mathis, \& Jackson. (2002). Manajemen Sumber Daya Manusia (Pertama). Salemba Empat.

Monoyasa, M. W., Sularso, R. A., \& Prihatini, D. (2017). Pengaruh Gaya Kepemimpinan Transformasional Kepala Sekolah Terhadap Kinerja Guru Sekolah Dasardengan Motivasidan Inovasi Guru Sebagai Variabel Intervening Dieks Kota Administratif. JURNAL RELASI STIE MANDALA JEMBER, 13(2), 315-335. http://jurnal.stiemandala.ac.id/index.php/relasi/article/downloa $\mathrm{d} / 120 / 107$

Mujiburrahman, Asmony, T., \& Husnan, H. (2017). Pengaruh Kepemimpinan Transformasional Dan Iklim Psikologis Terhadap Kesiapan Untuk Berubah Karyawan Puskesmas Kabupaten Lombok Barat Dalam Rangka Akreditasi Dan Komitmen Afektif Sebagai Variabel Intervening. JURNAL MAGISTER MANAJEMEN, 6(2), 1-19. https://doi.org/JURNAL MAGISTER MANAJEMEN

Ng, T. W. H. (2017a). Transformational leadership and performance outcomes: Analyses of multiple mediation pathways. The Leadership Quarterly, 28(3), 385-417. https://doi.org/10.1016/j.leaqua.2016.11.008

Ng, T. W. H. (2017b). Transformational leadership and performance outcomes: Analyses of multiple mediation pathways. Leadership Quarterly, 28(3), 385-417. https://doi.org/10.1016/j.leaqua.2016.11.008

Nguyen, T. T., Mia, L., Winata, L., \& Chong, V. K. (2017). Effect of transformational-leadership style and management control system on managerial performance. Journal of Business Research, 70, 202-213. https://doi.org/10.1016/j.jbusres.2016.08.018

Novitasari, D., Asbari, M., Sutardi, D., GazalI, \& Silitonga, N. (2020). Mempertahankan Kinerja Karyawan di Masa Pandemi Covid-19: Analisis Kesiapan untuk Berubah dan Efektivitas Kepemimpinan Transformasional. Value: 
Jurnal Manajemen Dan Akuntansi, 15(2), 2237.

https://doi.org/https://doi.org/10.32534/jv.v15i 2.1152

Novitasari, D., Asbari, M., Wijaya, M. R., \& Yuwono, T. (2020). Effect of Organizational Justice on Organizational Commitment: Mediating Role of Intrinsic and Extrinsic Satisfaction. International Journal of Science and Management Studies (IJSMS), 3(3), 96112. http://www.ijsmsjournal.org/currentissue.html

Novitasari, D., Sasono, I., \& Asbari, M. (2020). Work-Family Conflict and Worker's Performance during Covid-19 Pandemic: What is the Role of Readiness to Change Mentality? International Journal of Science and Management Studies (IJSMS), 3(4), 122-134. http://www.ijsmsjournal.org/volume3issue 4.html

Novitasari, D., Sasono, I., Santoso, J., Sudiyono, R. N., \& Asbari, M. (2020). Pengaruh Kesiapan untuk Berubah pada Karyawan Manufaktur: Analisis Praktik Kepemimpinan di Masa Pandemi Covid-19. JUMBO (Jurnal Manajemen , Bisnis Dan Organisasi ), 4(1), 175-188.

https://doi.org/http://dx.doi.org/10.33772/jumb o.v4i1.13260

Nugroho, Y. A., Asbari, M., Purwanto, A., Basuki, S., Sudiyono, R. N., Fikri, M. A. A., Hulu, P., Mustofa, Chidir, G., Suroso, \& Xavir, Y. (2020). Transformational Leadership and Employees' Performance: the Mediating Role of Motivation and Work Environment. EduPsyCouns: Journal of Education, Psychology and Counseling, 2(1), 438-460. https://ummaspul.e-

journal.id/Edupsycouns/article/view/507

Nuryanti, Y., Novitasari, D., Nugroho, Y. A., Fauji, A., Gazali, \& Asbari, M. (2020). Meningkatkan Komitmen Organisasional Dosen: Analisis Pengaruh Kepemimpinan Perguruan Tinggi dan Kepuasan Intrinsik \& Ekstrinsik Dosen. EduPsyCouns: Journal of Education, Psychology and Counseling, 2(1), 561-581. https://ummaspul.ejournal.id/Edupsycouns/article/view/551

Park, T., \& Pierce, B. (2020). Impacts of transformational leadership on turnover intention of child welfare workers. Children and Youth Services Review, 108, 104624. https://doi.org/10.1016/j.childyouth.2019.1046 24

Pramadani, A. B. (2012). Hubungan antara Komitmen Organisasi dengan Kesiapan untuk Berubah pada Karyawan Divisi Enterprise Service (DES) Telkom Ketintang Surabaya. Jurnal Psikologi Industri Dan Organisasi, 1(03), 112-119.
Prameswari, K. A. S., Sujana, W., \& Sapta, I. K. S. (2018). The Role of Motivation Mediation on Style Leadership and Organization Culture of Teacher Performance in SMP Negeri Kuta Utara Badung. International Journal of Contemporary Research and Review, 9(03), 20601-20609. https://doi.org/10.15520/ijcrr/2018/9/03/469

Purwanto, A., Asbari, M., Budi Santoso, P., Mayesti Wijayanti, L., Chi Hyun, C., Berman Sihite, O., \& Prameswari Saifuddin, M. (2020a). Pengaruh Gaya Kepemimpinan Partisipatif dan Otokratis Terhadap Kinerja Sistem Jaminan Halal HAS 23000 Pada Industri Makanan Kemasan. Edumaspul - Jurnal Pendidikan, 4(1). https://www.researchgate.net/publication/3394 70652_Pengaruh_Gaya_Kepemimpinan_Partis ipatif_dan_Otokratis_Terhadap_Kinerja_Siste m_Jaminan_Halal_HAS_23000_Pada_Industri _Makanan_Kemasan

Purwanto, A., Asbari, M., \& Hadi, A. H. (2020a). Gaya Kepemimpinan Perguruan Tinggi Kesehatan: Authentic, Tansformational, Authoritarian atau Transactional. Surya Medika Jurnal Ilmiah Ilmu Keperawatan Dan Ilmu Kesehatan Masyarakat, 15(1), 8-18. https://doi.org/10.32504/sm.v15i1.163

Purwanto, A., Asbari, M., \& Hadi, A. H. (2020b). Pengaruh Gaya Kepemimpinan Tansformational, Authentic, Authoritarian, Transactional Terhadap Kinerja Guru Pesantren di Tangerang. Dirasah, 3(1). https://ejournal.iaifa.ac.id/index.php/dirasah

Purwanto, A., Asbari, M., Prameswari, M., \& Ramdan, M. (2020b). Gaya Kepemimpinan Di Madrasah Aliyah: Authentic, Tansformational, Authoritarian Atau Transactional? Nidhomul Haq, 5, 15-31. https://doi.org/10.31538/ndh.v5i1.544

Purwanto, A., Asbari, M., Prameswari, M., Ramdan, M., \& Setiawan, S. (2020c). Dampak Kepemimpinan, Budaya Organisasi dan Perilaku Kerja Inovatif Terhadap Kinerja Pegawai Puskesmas. Jurnal Ilmu Kesehatan Masyarakat, 9(01), 19-27. https://doi.org/10.33221/jikm.v9i01.473

Purwanto, A., Asbari, M., \& Santoso, P. B. (2019). Influence of Transformational and Transactional Leadership Style toward Food Safety Management System ISO 22000:2018 Performance of Food Industry in Pati Central Java. Inovbiz: Jurnal Inovasi Bisnis, 7(2), 180 185. https://doi.org/10.35314/inovbiz.v7i2.1213

Purwanto, A., Asbari, M., Santoso, P. B., Wijayanti, L. M., Hyun, C. C., \& Pramono, R. (2020). Effect of Application ISO 38200:2018 Chain of Wood Products Custody toward Paper Company Competitiveness in Borneo Island Indonesia. International Journal of Science and 
Management Studies (IJSMS), April, 28-35. http://www.ijsmsjournal.org/2020/volume-3 issue-2/ijsms-v3i2p104.pdf

Purwanto, A., Bernarto, I., Asbari, M., Mayesti Wijayanti, L., \& Chi Hyun, C. (2020d). Effect of Transformational and Transactional Leadership Style on Public Health Centre Performance. Journal of Reseacrh in Business, Economics, and Education, 2(1), 304-314. http://e-journal.stie-kusumanegara.ac.id

Purwanto, A., Budi Santoso, P., \& Asbari, M. (2020). Effect Of Integrated ManagementaSystem Of ISO 9001:2015 And Iso 22000:2018 Implementation To Packaging Industries Quality Performance In Banten. Jurnal Ilmiah MEA (Manajemen, Ekonomi, Dan Akuntansi), 4(1), $17-29$.

https://doi.org/https://doi.org/10.31955/mea.vo 14.iss1.pp17-31

Purwanto, A., Mayesti Wijayanti, L., Chi Hyun, C., \& Asbari, M. (2019). the Effect of Tansformational, Transactional, Authentic and Authoritarian Leadership Style Toward Lecture Performance of Private University in Tangerang. DIJDBM, I(1), 29-42. https://doi.org/10.31933/DIJDBM

Purwanto, A., Pramono, R., Asbari, M., Senjaya, P., Hadi, A. H., \& Andriyani, Y. (2020e). Pengaruh Kepemimpinan terhadap Kinerja Guru Sekolah Dasar dengan Keterlibatan Kerja dan Budaya Organisasi sebagai Mediator. EduPsyCouns: Journal of Education, Psychology and Counseling, 2(1), 50-63. https://ummaspul.ejournal.id/Edupsycouns/article/view/412

Purwanto, A., Wijayanti, L. M., Choi, C. H., \& Asbari, M. (2019). the Effect of Tansformational, Transactional, Authentic and Authoritarian Leadership Style Toward Lecture Performance of Private University in Tangerang. $\quad$ DIJDBM, 1(1), 29-42. https://doi.org/10.31933/DIJDBM

Putri, M. D., \& Soedarsono, D. K. (2017). Pengaruh Kepemimpinan Transformasional Dan Employee Engagement Terhadap Kinerja Karyawan Direktorat Solution Operation Telkomsigma. E-Proceeding of Management : 4(3), 2541-2546.

Robbins, S. P. (2001). Organizational Behavior: Concept, Controversies, Aplications (8th Editio). Indeks Kelompok Gramedia.

Sari, P. O. (2018). Pengaruh Gaya Kepemimpinan Transformasional, Komitmen Afektif, Komitmen Kontinuans dan Komitmen Normatif terhadap Kesiapan Berubah (Studi Pada Bank BRI Kantor Wilayah Yogyakarta). EXERO : Journal of Research in Business and Economics, 1(1), 68-89. https://doi.org/10.24071/exero.2018.010104

Silitonga, N., Novitasari, D., Sutardi, D., Sopa, A.,
Asbari, M., Yulia, Y., Supono, J., \& Fauji, A. (2020). The Relationship of Transformational Leadership, Organizational Justice and Organizational Commitment: a Mediation Effect of Job Satisfaction. Journal of Critical Reviews, 7(19), 89-108. http://www.jcreview.com/?mno=101999

Siswatiningsih, I., Raharjo, K., \& Prasetya, A. (2019). Pengaruh Kepemimpinan Transformasional Dan Transaksional Terhadap Budaya Organisasi, Motivasi Kerja, Komitmen Oganisasional Dan Kinerja Karyawan. Jurnal Bisnis Dan Manajemen, 5(2), 146-157. https://doi.org/10.26905/jbm.v5i2.2388

Sudiyono, R. N., Fikri, M. A. A., Asbari, M., Suroso, Nugroho, Y. A., \& Singgih, E. (2020). The Role of Employee Engagement in the Relationship between Authentic Leadership , Talent Management and Job Satisfaction. International Journal of Advanced Science and Technology, 29(5), 11809-11836. http://sersc.org/journals/index.php/IJAST/artic le/view/25377

Susyanto, H. (2019). Pengaruh Kepemimpinan, Keterlibatan Karyawan dan Kepuasan Kerja terhadap Kesiapan untuk Berubah dalam Menghadapi Perubahan Organisasi. Jurnal Ekonomi, Bisnis, Dan Akuntansi (JEBA), 21(1), $1-20$.

Waruwu, H., Asbari, M., Purwanto, A., Nugroho, Y. A., Fikri, M. A. A., Fauji, A., Shobihi, A. W. I., Hulu, P., Sudiyono, R. N., Agistiawati, E., \& Dewi, W. R. (2020). The Role of Transformational Leadership, Organizational Learning and Structure on Innovation Capacity: Evidence from Indonesian Private Schools. EduPsyCouns: Journal of Education, Psychology and Counseling, 2(1), 378-397. https://ummaspul.ejournal.id/Edupsycouns/article/view/499

Wayan, N., Astiti, P., Wilian, S., \& Sridana, N. (2018). The Impacts Of Professional Allowances And Working Motivation Towards Teachers ' Working Performance At Senior High Schools In Mataram, Indonesia. 8(3), 6976. https://doi.org/10.9790/7388-0803046976

Yanthy, E., Purwanto, A., Pramono, R., Cahyono, Y., \& Asbari, M. (2020). Pengaruh Gaya Kepemimpinan Transformasional dan Tranksaksional Terhadap Kinerja Sistem Jaminan Halal HAS 23000. Jurnal Bisnis Dan Manajemen Islam, 8(1), 131-153. https://doi.org/http://dx.doi.org/10.21043/bisni s.v8i1.7045

Yue, C. A., Men, L. R., \& Ferguson, M. A. (2019). Bridging transformational leadership, transparent communication, and employee openness to change: The mediating role of trust. Public Relations Review, 45(3), 101779. https://doi.org/10.1016/j.pubrev.2019.04.012 
Yuwono, T., Novitasari, D., Hutagalung, D., Sasono, I., Silitonga, N., \& Asbari, M. (2020). Peran Organizational Justice terhadap Komitmen Organisasional: Analisis Mediasi Kepuasan Kerja Dosen Perguruan Tinggi Swasta. EduPsyCouns: Journal of Education, Psychology and Counseling, 2(1), 582-599. https://ummaspul.ejournal.id/Edupsycouns/article/view/550

Zain, A. N. D., \& Setiawati, T. (2019). Influence of Work Family Conflict and Job Satisfaction on Medical Employee Performance through Organizational Commitment. Review of Integrative Business and Economics Research, 8(1), 1-19. https://search.proquest.com/ docview/2088048618? accountid $=17242$ 